\title{
Section of the terminal filum for occult tethered cord syndrome: toward a scientific answer
}

\author{
Paul SteinboK, M.B.B.S., F.R.C.S.C., ${ }^{1,2}$ AND Andrew E. MacNeiLy, M.D., F.R.C.S.C. ${ }^{2,3}$ \\ Divisions of ${ }^{\prime}$ Neurosurgery and ${ }^{3}$ Urology, Department of Pediatric Surgery, British Columbia's \\ Children's Hospital, Children's and Women's Health Centre, Provincial Health Services Agency; and \\ ${ }^{2}$ Department of Surgery, University of British Columbia, Vancouver, British Columbia, Canada
}

\begin{abstract}
$\checkmark$ The concept of an occult tethered cord syndrome (OTCS), in which a normally located conus is tethered by the terminal filum, is controversial. Children with OTCS typically present with neurogenic urinary incontinence that has been refractory to medical management. Authors of a number of case series have suggested that section of the terminal filum may improve urinary symptoms, but the quality of the evidence supporting this treatment is not good.

The literature related to OTCS is reviewed and the progress toward a randomized controlled trial to assess the value of filum section in OTCS is detailed. A scientific answer to the question of filum section for OTCS awaits the results of an ongoing pilot randomized controlled trial and a more definitive trial to follow.
\end{abstract}

(DOI: $10.3171 /$ FOC-07/08/E5)

\author{
KEY WORDS • occult tethered cord syndrome • spinal dysraphism • surgery • \\ terminal filum • urinary incontinence
}

$\mathrm{T}$ HE ENTITY OF A TETHERED CORD SYNDROME secondary to a tight terminal filum has been well defined for many years ${ }^{7,9,21}$ and is generally accepted by pediatric neurosurgeons. ${ }^{27}$ The pathogenesis of the tethered cord syndrome is thought to be traction on the lower end of the spinal cord by a thickened terminal filum. This traction on the conus leads to decreased blood flow and decreased oxidative metabolism, which may result in the clinical symptoms and signs of the tethered cord syndrome. ${ }^{37}$ The clinical features of the syndrome include neurological, musculoskeletal, and urological abnormalities, which are often reversed or improved by section of the filum. The tethered cord syndrome is typically associated with a low-lying conus medullaris, with the tip of the conus located below the L-2 vertebral level. The thickening of the filum and subsequent tethering of the spinal cord are thought to result from abnormal development of the filum during the retrogressive differentiation phase of secondary neurulation. As such, other evidence of spinal dysraphism, such as midline lumbar or sacral cutaneous lesions and osseous spina bifida, are commonly identified in this population of patients. In children with the typical tethered cord syndrome associated with a low-lying conus and a thickened filum, the majority of pediatric neurosurgeons would recommend section of the terminal filum. ${ }^{27}$ This operation is relatively safe, taking less than 1 hour to complete, and entails almost no risks.

More recently, the concept of a tethered cord syndrome in which the conus is not low has been proposed. The initial report of this concept was by Khoury et al. in 1990. ${ }^{11}$

Abbreviation used in this paper: OTCS = occult tethered cord syndrome.
They reported a series of 31 children with urodynamically demonstrated bladder instability unresponsive to conservative management in whom imaging examination (plain film and computed tomography myelography) showed osseous spina bifida occulta, but a conus in normal position. Because the clinical findings of neurogenic bladder dysfunction were similar to those in patients with the usual tethered cord syndrome, characterized by the conus in an abnormally low position, a tentative diagnosis of tethered cord syndrome was entertained. The fila were cut, and significant postoperative resolution of urological symptoms occurred in $70 \%$ of the patients. There have followed a number of reports of clinical series of children with findings suggestive of a tethered cord syndrome, but in whom the conus was found on neuroimaging to be in a normal position. In those children, section of the terminal filum resulted in improvement in the clinical findings. ${ }^{18,}$ ${ }^{33,34}$ In almost all cases, the primary clinical abnormality has been refractory urinary incontinence, which has been considered neurogenic in origin. In some series, surgical intervention has been considered only when there have been additional manifestations of occult spinal dysraphism, such as a cutaneous abnormality and/or the filum being found on magnetic resonance images to be thicker than the normal $2 \mathrm{~mm}$ and to exhibit a signal consistent with fat - a so-called fatty filum. ${ }^{33,34}$ In other series, however, the presence of persistent bladder dysfunction per se, based on clinical and/or urodynamic assessments, has been enough to justify surgical section of the filum. ${ }^{16,18,23,24,35}$ In the studies under discussion, the rate of improvement for urinary symptoms has varied from $60 \%{ }^{24}$ to as high as $97 \%$ 18,35 (Table 1).

Thus far, the reports of beneficial effects of filum sec- 
tion in children with OTCS and urinary incontinence are either anecdotal or case series, and there is no good scientific evidence that cutting the filum in such children is beneficial. Part of the difficulty of drawing conclusions from the reported case series is the fact that urinary incontinence in the school-age child is common, and most-but not all-cases resolve spontaneously, showing gradual improvement over time. ${ }^{22}$

The pathophysiology of OTCS, in which there is no anatomical evidence of a low-lying conus and in which the terminal filum is often normal, is difficult to understand, and the indications for section of the filum in this context has been controversial. ${ }^{20}$ If OTCS exists as a distinct entity, one has to postulate that the conus can be tethered by the filum and still be in a normal location. One might argue that the conus could be slightly lower than it otherwise would have been had it not been tethered and still be located normally. Whatever the location of the termination of the conus, one would expect that the filum would have to be less elastic than normal in order to pull on the conus abnormally. This possibility is supported by two studies in which histopathological examinations of the fila from patients with OTCS showed excess fibrous tissue and fat compared with normal fila. ${ }^{25,26}$

A recent survey of pediatric neurosurgeons done in December 2005 was revealing in this regard. ${ }^{27}$ When presented with a child with neurogenic urinary incontinence documented by urodynamic testing, a low-lying conus, and a thickened fatty filum, more than $90 \%$ of neurosurgeons attending a pediatric neurosurgical conference agreed that such a patient had cord tethering and said they would recommend section of the filum. On the other hand, when presented with a patient with the identical history, but with a normal conus and filum, the same respondents had major disagreements as to whether the spinal cord could be tethered in this situation and whether or not section of the filum should be recommended in patients fitting the criteria of OTCS. ${ }^{27}$

\section{Randomized Controlled Trial}

In the light of the ongoing controversy, it was thought that a randomized controlled clinical trial was required to provide scientific evidence about the value of surgical sectioning of the filum in children with OTCS who presented with a primary symptom of urinary incontinence. With that in mind, a working group comprising pediatric neurosurgeons, urologists, neuroradiologists, and clinical epidemiologists convened in Vancouver, British Columbia in February 2004. The result of this meeting was a draft proposal for a multicenter, randomized, controlled clinical study to compare the regimen of symptomatic medical treatment only with a regimen of surgical section of the terminal filum plus symptomatic medical treatment in children with neurogenic urinary incontinence as part of a suspected OTCS.

The members of the working group believed that such a study would be of major clinical importance. Urinary incontinence in the school-age child is a common problem, with a prevalence of 8 to $16 \% .^{1,29,30}$ The prevalence decreases with increasing age, $, 0,22,30,38$ but urinary incontinence may persist into adulthood. The incidence of urinary incontinence in young, healthy patients is surprising- ly high, and females are more affected than males. In a study of 4200 healthy nursing students 17 to 25 years of age, a $51 \%$ incidence of intermittent episodes of incontinence was reported, with $16 \%$ of the participants having major or regular urine loss. ${ }^{36}$ In a recent study, $26 \%$ of Japanese women under 30 years of age and $40 \%$ over 40 years had urinary incontinence. ${ }^{8}$ Incontinence in males younger than 30 years of age is reported to range from 6 to $10 \% ., 5,12,31$ In a study of 20,000 patients older than 5 years of age in a general medical practice, $27.6 \%$ of girls and women and $10.8 \%$ of boys and men surveyed reported urinary incontinence. ${ }^{31}$ More than $15 \%$ of girls and women and more than $3 \%$ of boys and men from each decade of life were affected. Interestingly, incontinence was noted in the practice records of fewer than $0.1 \%$ of these patients. ${ }^{31}$ Similarly, in the Japanese study mentioned above, only $4 \%$ of women with incontinence discussed the symptom with their physicians, with the major reasons cited being shame and resignation. ${ }^{8}$ Patients tend not to discuss the issue of incontinence because of embarrassment and low expectations for treatment, even though it may have a profound impact on their quality of life. ${ }^{10}$ The presence of such a high prevalence of idiopathic urinary incontinence in the young, adult population leads one to question whether persistence or exacerbation of childhood incontinence is more common than usually thought. Furthermore, whether this incontinence is a major health problem or a normal state of being is routinely debated amongst urologists.

Attesting to the importance of the problem of childhood urinary incontinence, as reported in a systematic review by Sureshkumar et al. ${ }^{28}$ in 2003, there have been several prior randomized controlled trials on the treatment of childhood daytime urinary incontinence investigating the efficacy of tolterodine (two studies), daytime alarms (one study), imipramine (one study), and biofeedback/oxybutinin (one study). All of these prior studies, which evaluated various forms of medical treatments, have had negative results..$^{28}$ The results of a randomized controlled study evaluating section of the filum terminale would determine if section of the filum was any better than the natural history in improving urinary incontinence in a defined population of children. If the results of the study are negative, the findings should limit the expansion of this procedure for what is a very common problem. If the study results are positive, the study would validate a treatment that has the potential to benefit many children and possibly many adults who have accepted their urinary incontinence as an untreatable disorder.

After some modifications of the initial proposal, a pilot randomized controlled trial at three centers in Canada (Vancouver, Ottawa, and Toronto) was funded by the British Columbia Medical Services Foundation, and patient accrual into this study started in July 2006. The hypothesis for the study is that surgical section of the terminal filum, when added to standard medical therapy, will result in a reliable and clinically significant improvement in urinary incontinence compared with the results of standard medical therapy over a 12 -month period.

The target population of this study is children who are between 5 and 18 years of age, have primary or secondary daytime urinary incontinence, and whose symptoms have not improved adequately despite compliance with 12 
TABLE 1

Previously reported case series involving filum section with conus in normal location*

\begin{tabular}{|c|c|c|c|c|}
\hline Authors \& Year & No. of Cases & $\begin{array}{l}\text { Urological Outcomes Reported } \\
\text { Following Filum Section }\end{array}$ & Follow-Up (mos) & Comments/Criticisms \\
\hline Khoury et al., 1990 & 31 & $\begin{array}{l}\text { incontinence resolved in } 72 \% \\
\text { urodynamic hyperreflexia resolved in 59\% } \\
\text { urodynamic compliance improved in 66\% }\end{array}$ & mean 13.3 & $\begin{array}{l}\text { imaging w/ KUB \& CT myelography; } \\
\text { pts had a variety of lower limb signs \& Sx; } \\
4 \text { pts actually had a low-lying conus; } \\
\text { no objective measure of incontinence used }\end{array}$ \\
\hline Warder \& Oakes, 1993 & 13 & Sx improved in 3 of the 4 pts w/ urinary Sx & range $6-72$ & $\begin{array}{l}\text { no urodynamic testing performed; } \\
\text { only } 4 \text { pts had primary urinary symptoms; } \\
\text { no objective measure of incontinence used }\end{array}$ \\
\hline Nazar et al., 1995 & 32 & $\begin{array}{l}\text { normalization of voiding pattern } 64 \% \\
>50 \% \text { improvement in frequency/urgency } \\
\text { in } 32 \%\end{array}$ & range $2-48$ & $\begin{array}{l}\text { only } 20 / 32 \text { pts underwent urodynamic testing; } \\
\text { urodynamic assessment qualitative; } \\
\text { no objective measure of incontinence used }\end{array}$ \\
\hline Selcuki et al., 2000 & 17 & $\begin{array}{l}\text { improvement in both bladder } \\
\text { Sx \& urodynamics in } 59 \%\end{array}$ & mean 18 & $\begin{array}{l}\text { pre- \& postop urodynamics not described; } \\
\text { no objective measure of incontinence used }\end{array}$ \\
\hline Selcuki et al., 2003 & 8 & normalized/improved urodynamics in $7 / 8$ & range $3-84$ & $\begin{array}{l}\text { all pts presented w/ refractory incontinence; } \\
\text { no assessment of postop incontinence }\end{array}$ \\
\hline Wehby et al., 2004 & 60 & $\begin{array}{l}\text { incontinence resolved in } 52 \% \\
\text { marked improvement in incontinence in 35\% } \\
\text { resolution or improvement in urgency/ } \\
\text { frequency in } 100 \%\end{array}$ & mean 13.9 & $\begin{array}{l}\text { no urodynamic testing performed; } \\
\text { no objective measure of incontinence used }\end{array}$ \\
\hline Metcalfe et al., 2006 & 36 & $\begin{array}{l}\text { incontinence resolved in } 42 \% \\
\text { improvement in urinary Sx in } 72 \% \\
\text { urodynamic improvement in 59\% }\end{array}$ & mean 49 & $\begin{array}{l}\text { excellent urodynamic assessment } \& \text { follow-up; } \\
\text { all pts had abnormal pre-op urodynamics; } \\
\text { no objective measure of incontinence used }\end{array}$ \\
\hline Selden et al., 2006 & 6 & $\begin{array}{l}\text { normalized/improved urodynamics in } 4 / 6 \\
\text { qualitatively improved voiding function in } 6 / 6\end{array}$ & range $3-30$ & no objective measure of incontinence used \\
\hline
\end{tabular}

$* \mathrm{KUB}=$ kidney-ureter-bladder; pts $=$ patients; $\mathrm{Sx}=$ symptoms.

months of standard medical therapy under the supervision of a urologist. Children must have abnormal results of urodynamic testing performed in a standardized manner. There have to be a minimum of two of the following abnormalities: 1) abnormally low total bladder volume normalized for age; 2) abnormal bladder compliance (excessive pressure volume characteristics); 3) involuntary detrusor overactivity as determined by the pediatric urologist performing the study; and 4) abnormal bladder sensation with the volume at first sensation less than $50 \%$ of expected total bladder capacity for age. Patients are excluded if they have any of the following: anatomical lower urinary tract outflow obstruction demonstrated on a voiding cystourethrogram and/or cystoscopic examination; an alternative diagnosis recognized as associated with neurogenic bladder dysfunction such as myelomeningocele, lipomyelomeningocele, or other spinal dysraphic state, spinal cord injury, or cerebral palsy or other traumatic brain injury; congenital anorectal malformations including imperforate anus; or urodynamic evidence of an atonic bladder, as evidenced by bladder capacity of greater than $125 \%$ of expected volume.

The most important neuroimaging inclusion criterion is a normal position of the conus medullaris, defined as the tip of the conus medullaris being located above the inferior L-2 endplate. Patients can be included in the study irrespective of the thickness of the filum, the presence of fat in the filum, a lumbar or sacral bifid spine, or a terminal syringomyelia. It was the opinion of the group members that in the presence of a normally positioned conus the significance of these other imaging findings usually associated with a tethered spinal cord was uncertain. ${ }^{2,19,32}$ Nevertheless, because a thickened fatty filum could act as a confounding factor in the results, the plan is to stratify the sample based on the presence of imaging evidence of fat or thickening in the terminal filum. Patients are excluded if they have recognized spinal dysraphic states, including lipomyelomeningocele, myelomeningocele, meningocele, dermal sinus tract, split cord malformation, or caudal regression syndromes or if they have any other specific spinal cord abnormality or malformation that would readily explain the patient's symptoms (for example, a tumor).

One of the most contentious issues in planning this study was the choice of a suitable primary outcome measure. Ideally, the outcome measure should assess the extent of urinary incontinence, which is what the treatment was designed to improve and what the majority of patients and/or their parents are concerned about. Unfortunately, there was no such outcome measure available at the time this was discussed in detail at the Vancouver workshop. As a result, a urodynamic summary score, based on measurements of bladder volume, compliance, detrusor activity, and bladder sensation, was developed as the primary outcome. The urodynamic summary score is a modification, based on the opinion of the urological experts, of a similar recently published score that was found to change responsively after tethered cord release in patients with documented spinal dysraphism. ${ }^{17}$ The modified urodynamic summary score has been found to have excellent inter- and intrarater reliability. ${ }^{15}$ More recently, a validated enuresis-specific quality-of-life scale has been added as a second and probably more important primary outcome measure. ${ }^{13,14}$

A number of secondary outcomes are being assessed. These include the Dysfunctional Voiding Symptom Score, ${ }^{3}$ the frequency and volume of voids, and urinary urgency on 
a visual analog scale, as well as the frequency of urinary tract infections. It is planned to analyze whether radiographic findings of a fatty and/or thickened filum or clinical findings, such as mild neurological lower limb abnormalities or duration of urinary incontinence, correlate with outcome.

\section{Conclusions}

Much progress has been made in attempting to obtain a scientific answer to whether or not section of the terminal filum as a treatment for refractory urinary incontinence in children with presumed OTCS is effective. A pilot randomized controlled trial commenced in 2006, and the plan is to expand this trial into a definitive clinical trial. A scientific answer may not be available until these randomized controlled trials are completed.

\section{References}

1. Bakker E, van Sprundel M, van der Auwera JC, van Gool JD, Wyndaele JJ: Voiding habits and wetting in a population of 4,332 Belgian schoolchildren aged between 10 and 14 years. Scand J Urol Nephrol 36:354-362, 2002

2. Bulsara KR, Zomorodi AR, Enterline DS, George TM: The value of magnetic resonance imaging in the evaluation of fatty filum terminale. Neurosurgery 54:375-380, 2004

3. Farhat W, Bägli DJ, Capolicchio G, O'Reilly S, Merguerian PA, Khoury A, et al: The dysfunctional voiding scoring system: quantitative standardization of dysfunctional voiding symptoms in children. J Urol 164:1011-1015, 2000

4. Feneley RC, Shepherd AM, Powell PH, Blannin J: Urinary incontinence: prevalence and needs. Br J Urol 51:493-496, 1979

5. Hampel C, Wienhold D, Benken N, Eggersmann C, Thüroff JW: Definition of overactive bladder and epidemiology of urinary incontinence. Urology 50:4-17, 1997

6. Hellstrom A, Hanson E, Hansson S, Hjälmäs K, Jodal U: Micturition habits and incontinence at age 17 -reinvestigation of a cohort studied at age 7. Br J Urol 76:231-234, 1995

7. Hendrick EB, Hoffman HJ, Humphreys RP: The tethered spinal cord. Clin Neurosurg 30:457-463, 1983

8. Hirai K, Sumi T, Kanaoka Y, Ishiko O: Female urinary incontinence: diagnosis, treatment and patients' concerns. Drugs Today (Barc) 38:487-493, 2002

9. Hoffman HJ, Hendrick EB, Humphreys RP: The tethered spinal cord: its protean manifestations, diagnosis and surgical correction. Childs Brain 2:145-155, 1976

10. Jackson S: The patient with an overactive bladder-symptoms and quality-of-life issues. Urology 50:18-24, 1997

11. Khoury AE, Hendrick EB, McLorie GA, Kulkarni A, Churchill BM: Occult spinal dysraphism: clinical and urodynamic outcome after division of the filum terminale. J Urol 144: 426-429, 443-424, 1990

12. Lagace EA, Hansen W, Hickner JM: Prevalence and severity of urinary incontinence in ambulatory adults: an UPRNet study. $\mathbf{J}$ Fam Pract 36:610-614, 1993

13. Landgraf JM: Precision and sensitivity of the short-form pediatric enuresis module to assess quality of life (PEMQOL). J Pediatr Urol 3:109-117, 2007

14. Landgraf JM, Abidari J, Cilento BG, Cooper CS, Schulman SL, Ortenberg J: Coping, commitment, and attitude: quantifying the everyday burden of enuresis on children and their families. Pediatrics 113:334-344, 2004

15. MacNeily A, Leonard M, Metcalfe PD, Casale A, Guerra L, Steinbok P, et al: Development of an objective score to quantify the pediatric cystometrogram. J Urol (in press, 2007)

16. Metcalfe PD, Luerssen TG, King SJ, Kaefer M, Meldrum KK, Cain MP, et al: Treatment of the occult tethered spinal cord for neuropathic bladder: results of sectioning the filum terminale. J Urol 176: 1826-1830, 2006

17. Meyrat BJ, Tercier S, Lutz N, Rilliet B, Forcada-Guex M, Vernet $\mathrm{O}$ : Introduction of a urodynamic score to detect pre- and postoperative neurological deficits in children with a primary tethered cord. Childs Nerv Syst 19:716-721, 2003

18. Nazar GB, Casale AJ, Roberts JG, Linden RD: Occult filum terminale syndrome. Pediatr Neurosurg 23:228-235, 1995

19. Okumura R, Minami S, Asato R, Konishi J: Fatty filum terminale: assessment with MR imaging. J Comput Assist Tomogr 14:571-573, 1990

20. Pang D: Occult filum terminale. Pediatr Neurosurg 23:227, 1995

21. Pang D, Wilberger JE: Tethered cord syndrome in adults. J Neurosurg 57:32-47, 1982

22. Saedi NA, Schulman SL: Natural history of voiding dysfunction. Pediatr Nephrol 18:894-897, 2003

23. Selçuki M, Coskun K: Management of tight filum terminale syndrome with special emphasis on normal level conus medullaris (NLCM). Surg Neurol 50:318-322, 1998

24. Selçuki M, Unlü A, Ugur HC, Soygür T, Arikan N, Selçuki D: Patients with urinary incontinence often benefit from surgical detethering of tight filum terminale. Childs Nerv Syst 16: 150-154, 2000

25. Selçuki M, Vatansever S, Inan S, Erdemli E, Bagdatoglu C, Polat A: Is a filum terminale with a normal appearance really normal? Childs Nerv Syst 19:3-10, 2003

26. Selden NR, Nixon RR, Skoog SR, Lashley DB: Minimal tethered cord syndrome associated with thickening of the terminal filum. J Neurosurg 105 (3 Suppl):214-218, 2006

27. Steinbok P, Garton HJ, Gupta N: Occult tethered cord syndrome: a survey of practice patterns. J Neurosurg 104 (5 Suppl):309-313, 2006

28. Sureshkumar P, Bower W, Craig JC, Knight JF: Treatment of daytime urinary incontinence in children: a systematic review of randomized controlled trials. J Urol 170:196-200, 2003

29. Sureshkumar P, Craig JC, Roy LP, Knight JF: Daytime urinary incontinence in primary school children: a population-based survey. J Pediatr 137:814-818, 2000

30. Swithinbank LV, Brookes ST, Shepherd AM, Abrams P: The natural history of urinary symptoms during adolescence. $\mathbf{B r} \mathbf{J}$ Urol 81 (3 Suppl):90-93, 1998

31. Thomas TM, Plymat KR, Blannin J, Meade TW: Prevalence of urinary incontinence. Br Med J 281:1243-1245, 1980

32. Uchino A, Mori T, Ohno M: Thickened fatty filum terminale: MR imaging. Neuroradiology 33:331-333, 1991

33. Warder DE, Oakes WJ: Tethered cord syndrome and the conus in a normal position. Neurosurgery 33:374-378, 1993

34. Warder DE, Oakes WJ: Tethered cord syndrome: the lowlying and normally positioned conus. Neurosurgery 34: 597-600, 1994

35. Wehby MC, O’Hollaren PS, Abtin K, Hume JL, Richards BJ: Occult tight filum terminale syndrome: results of surgical untethering. Pediatr Neurosurg 40:51-58, 2004

36. Wolin LH: Stress incontinence in young, healthy nulliparous female subjects. J Urol 101:545-549, 1969

37. Yamada S, Iacono RP, Andrade T, Mandybur G, Yamada BS: Pathophysiology of tethered cord syndrome. Neurosurg Clin N Am 6:311-323, 1995

38. Yeung CK, Sreedhar B, Sihoe JD, Sit FK, Lau J: Differences in characteristics of nocturnal enuresis between children and adolescents: a critical appraisal from a large epidemiological study. BJU Int 97:1069-1073, 2006

Manuscript submitted May 19, 2007.

Accepted June 21, 2007.

Address reprint requests to: Paul Steinbok, M.B.B.S., Division of Pediatric Neurosurgery, 4480 Oak St, \#K3-159, Vancouver, BC, Canada, V6H 3V4. email: psteinbok@cw.bc.ca. 